\title{
Exciting Young Students In Grades K-8 About STEM Through An Afterschool Robotics Challenge
}

\author{
Tanja Karp, Texas Tech University, USA \\ Patricia Maloney, Texas Tech University, USA
}

\begin{abstract}
In this paper, we describe the successful implementation of an afterschool LEGO robotics program for elementary and middle school students that is annually offered by the Whitacre College of Engineering at Texas Tech University. Three events are held on campus: the kickoff, a trial run, and the competition, spread over a period of eight weeks. In between the events, participants design their LEGO robots at the school, mostly during afterschool clubs. Through our program, we broaden the participation in hands-on robotics tasks which apply STEM concepts to groups that otherwise might not have the opportunity. Success factors of our implementation are the flexibility of the implementation at the local level, the inclusion of engineering students as mentors and volunteers, and the low cost for organizers and participants. We provide evidence that we have reached a diverse student population in grades $K-8$ and positively changed their attitudes toward STEM, then we report the benefits that teachers see in regular participation in the event. Finally, we describe the benefit of involving engineering undergraduate students as mentors and volunteers.
\end{abstract}

Keywords: LEGO Robotics Competition, K-8; Reaching Underserved Student Population; Afterschool Programs

INTRODUCTION

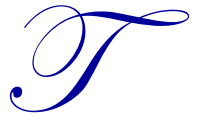

he field of robotics is interdisciplinary per se and thus lends itself to teach science, technology, engineering, and math (STEM) concepts in an interconnected way and through hands-on experiential learning. In addition, many robotics kits, such as the LEGO Mindstorms NXT kits, remind children of toys they know from at home and thus immediately engage them in a playful way and keep them engaged for extended time periods (Mauch, 2001)

Robotics programs have been proven to be successful tools to engage students in K-12 in STEM and create interest in careers in the STEM field (Hobson, 2000; Mitchell, Warwick, Browne, Gasson, \& Wyatt, 2010; Habash, Suurtamm, 2010) that is then supported by a variety of scholarships available to college applicants with robotics experience. ${ }^{1}$ Robotics has also been recognized as a topic that easily excites college level engineering students, offers hands-on experience to support theoretical concepts, and fosters multidisciplinary work (Mitchell et al., 2010; Grimes \& Seng, 2008; Caron, 2010). LEGO robotics in particularly has seen a wide implementation in K-12 as an exciting, hands-on way to apply and reinforce science concepts (Franz \& Elmore, 2009; Williams, Ma, Prejean, Ford, \& Lai, 2007) and improve problem solving skills (Mauch, 2001; Robinson, 2005). It has also been successfully used in preservice teacher education (Chambers and Carbonaro 2003). Nugent, Barker, \& Grandgenett (2012) showed the effectiveness of using LEGO robotics to teach science, engineering, and technology concepts in after school 4-H clubs in rural Nebraska with participants aged 9-11 years old.

\footnotetext{
1 FIRST Robotics Scholarships, https://my.usfirst.org/scholarships/index.lasso?page=scholarshipsearch printed, accessed February 11, 2013.
} 
This paper describes an afterschool robotics challenge, Get Excited About Robotics (GEAR), which is annually offered by the Whitacre College of Engineering (WCOE) at Texas Tech University (TTU) with the goal of exciting young elementary and middle school students about careers in STEM and engineering in particular through hands-on challenges that foster problem solving skills, team work, critical thinking, and self-efficacy. Over the last years this program has seen significant growth in participation, particularly among schools from small school districts in rural areas. As opposed to other robotics challenges, the program is not stand-alone but connects teachers and participants with engineering undergraduate students and faculty.

We will report evidence of a successful implementation that reaches out to a diverse participant body and a large percentage of Title 1 schools, i.e. schools receiving funds under the Title I of the Elementary and Secondary Education Act (1965) to improve academic achievement of the disadvantaged. In other research, Title 1 status has generally been accepted as an indicator of low socioeconomic status for students (Bardack, Seidel, Seiter, \& Lampron, 2011). We also report benefits of participation as stated by teachers, and the format in which engineering students are involved.

While the best case scenario would be to have evidence that participation in GEAR increases the participants' performance in STEM disciplines and their likelihood to choose a career in this field, this is beyond the scope of this paper due to chronological constraints. Additionally, selection criteria at the participating schools are too different to ensure that students who have a continued interest in STEM also have the opportunity of continued participation in GEAR and other robotics programs. Also, student self-selection is a possible confounding factor: at most schools, students must choose to take part in this program, and it is likely that the populations of students who do so materially differ in important ways from those who do not, e.g. they might already have a higher interest in STEM activities. Therefore, it is most appropriate to observe effects of this program on students while they participate in order to observe immediate factors in a low-cost and authentic manner.

\section{GET EXCITED ABOUT ROBOTICS (GEAR)}

GEAR $^{2}$ is a 6-8 week LEGO robotics challenge for students in elementary and middle school currently offered at several locations in Texas ${ }^{34}$ on an annual basis. It uses the LEGO MINDSTORMS NXT kits ${ }^{5}$, which include a programmable brain, motors, several sensors (sound, light, touch, ultrasonic) in addition to typical LEGO bricks, beams, connectors, and axles. The theme of the competition changes every year and is motivated by real world applications of robotics. It is developed and provided by a 501 (c) 3 volunteer organization ${ }^{6}$. Previous years' themes included a science station in Antarctica, automated farming, and the maintenance of energy infrastructure. On game day at the end of the 6-8 weeks period, teams compete on an $8^{\prime} \times 8^{\prime}$ table in two minute rounds during which they need to accomplish as many of the tasks as possible, each of which is associated with a score related to its difficulty. While GEAR is in many aspects similar to Junior FIRST LEGO League ${ }^{7}$, the major difference is that it empowers the tournament organizers by providing flexibility in the organization to best meet local needs. The general GEAR rules are 12 pages, which include all judging and scoring rules, and a description of all types of awards. The annual challenge description is of similar length and includes a description of all tasks, the scores associated with them, and instructions on where to buy game pieces and how to assemble them. Degrees of flexibility for the organizers include timing of the competition, number of teams allowed per school, fees charged, and services provided by the organizers to the participants.

Our GEAR tournament has been hosted by the Whitacre College of Engineering since 2006 and has seen continued growth in participation and continued financial support from various entities. The competition typically kicks off during Engineers' Week ${ }^{8}$ in February and runs through the middle of April with the competition being held

\footnotetext{
${ }^{2}$ Get Excited About Robotics (GEAR), http://www.gearrobotics.org, accessed February 2013.

${ }^{3}$ Get Excited About Robotics (GEAR) at Texas Tech University, http://www.coe.ttu.edu/stem/gear/, accessed February 2013.

${ }^{4}$ Get Excited About Robotics, University of Texas in San Antonio, http://itec.utsa.edu/, accessed February 2013.

${ }^{5}$ LEGO MINDSTORMS, http://www.mindstorms.lego.com/, accessed February 2013.

${ }^{6}$ Get Excited About Robotics (GEAR), http://www.gearrobotics.org, accessed February 2013.

${ }^{7}$ FIRST LEGO League (FLL), http://firstlegoleague.org/, accessed February 2013.

${ }^{8}$ National Engineers Week Foundation, http://www.eweek.org/, accessed February 2013.
} 
during National Robotics Week. ${ }^{9}$ It consists of three events all held on the TTU campus: During the kickoff event, the annual challenge is revealed and related to real-world engineering problems through short presentations given by professionals. Each school receives a set of game pieces, a game mat, and the rules. Participants then start designing, programming, and testing their robots at school, mostly in afterschool programs. However, some schools also incorporate the competition into elective courses such as technology or robotics, or offer it as part of the Texas Gifted and Talented (GT) program. Participants meet 1 - 5 times per week for 30 - 90 minutes each. Participants return to campus for a trial run under real competition settings toward the end of March. This event provides them with the opportunity to learn from other teams and evaluate their performance. Finally, teams return to campus after eight weeks for game day when they compete for awards. The competition consists of four seeding rounds and then finals in which the eight highest ranked teams participate. In addition to first to fourth place awards, there are a variety of other awards ranging from best themed team to a young engineering award ${ }^{10}$.

Participation in the TTU GEAR competition is at no cost other than time and travel and is open to any public or private school or homeschool group that registers. A teacher is required as coach for school teams as the point of contact for the organizers. Participating schools enjoy the same flexibility in the implementation of GEAR at their school as we have in the organization of the tournament. They decide on the selection of participants, meeting times, total number of teams and participants (there is an upper limit of 10 teams per school). They find computing facilities at school and organize the trips to campus. Over the years, the organizers have acquired over 150 LEGO MINDSTORMS NXT kits and each school can check out up to six kits for the duration of the competition at no cost. This has allowed schools to evaluate participation in robotics and its benefits before making a significant financial investment. It also enables small rural schools and Title 1 schools that would otherwise not have the resources to participate to do so.

In addition, schools in proximity to the university campus have the option to request engineering mentors to assist their teams. Mentors are engineering freshmen enrolled in a service learning section of ENGR 1315: Introduction to Engineering, a college wide freshman level introductory course. Descriptions of service learning courses for engineering freshmen can be found in Osborne, Thomas, \& Forbes (2010) and Karp (2011).

\section{METHODOLOGY AND DATA}

Data for this paper were collected through multiple qualitative and quantitative means: participant observation; registration forms; team demographic reports that required open-ended answers to questions; interviews with students, engineering undergraduate mentors, and teachers; and a pre/post-test survey that measured student attitude shifts over the duration of the program. Schools were all located in the West Texas region, see Figure 3 below, and opted into this program after hearing about it through notifications via email, through information sessions conducted by the organizer, and through the teachers' interpersonal socio-professional network.

In 2011 and 2012, team information was collected from the coaches. In 2011, 31 of 35 schools submitted their team information sheet reporting 511 participants, and in 2012, 38 of 49 schools reported 471 participants. Since the inception of the program at TTU in 2006, over 60 schools ( 28 elementary and 35 middle schools) chose to participate, this allowed for an overall student sample of over 1500 participants. Undergraduate mentors were initially attracted through payment, then, in subsequent years, were compensated through a freshmen-level servicelearning course credit of a required engineering class (Karp, 2011). Over six years, over 150 engineering undergraduate mentors participated. Engineering undergraduate students who served as team mentors were expected to complete 15 hours with their school teams and document their mentoring experience in a journal. They also had to write three reflection papers in which they evaluated skills required in engineering (soft and hard), and the connection between GEAR tasks their teams perform and the engineering profession.

Interviews and participant observation were conducted during practices and competitions. Written data, such as the team reports and registration forms were collected at the beginning and end of the program. In 2010

\footnotetext{
${ }^{9}$ National Robotics Week, http://www.nationalroboticsweek.org/, accessed February 2013.

10 GEAR General Documents, http://www.gearrobotics.org/jm/index.php?option=com wrapper\&view=wrapper\&Itemid=71, accessed February 2013.
} 
(year five of conducting this program), we wished to have a formal metric of student learning and attitude shift over the course of the program and so decided to conduct a pre- and post-test survey of participants. This survey was designed by Nugent et al. (2009) and students were asked the same 25 questions at the beginning and the end of the program. All answers were entered on a Likert scale ranging from 'strongly agree' (5) to 'strongly disagree' (1). Participation was voluntary, and 16 of the 24 schools that were in the program that year completed both the pre- and post-test. Of the approximately 400 students who were enrolled in the program in 2010, 300 took the pre-test and 225 of that 300 took the post-test, thereby resulting in an overall response rate of over $50 \%$. As part of the survey we collected the students' gender, ethnicity, socio-economic status, grade level, and prior experience with LEGO robotics (Karp \& Schneider, 2011).

Data were analyzed through multiple means. The qualitative data were analyzed through grounded theory (Glaser and Strauss, 1967; Charmaz, 2006) whereby themes emerged holistically from repeated reviews of the verbal and written responses of teachers and students. These themes were then tested through specific questions asked to students, teachers, and undergraduate mentors for accuracy and authenticity. The quantitative data (gathered from formal surveys, team demographic sheets, and registration forms) were entered into data analysis software, and then analyzed through paired two-tailed paired t-tests to determine the program's effect on students and student sub-groups (for specifics and results, see section $\mathrm{C}$ in Chapter 4 below).

\section{EVIDENCE OF SUCCESSFUL IMPLEMENTATION OF AN AFTERSCHOOL ROBOTICS PROGRAM}

The best planned program is useless without data that supports its efficacy. That is, to determine the usefulness of this program, we need to know to what extent GEAR participation is attractive to teachers, engineering undergraduate mentors, and participants and what effect it has on the latter. Generally, through growth in participation over the six years of the program's existence, team demographics, and teacher and engineering undergraduate mentor perceptions, we find that the program excites traditionally underrepresented student participants about STEM and engineering in particular and teaches both K-8 and undergraduate students valuable skills such as teamwork, problem solving, and critical thinking. In the short term, our data indicate that our afterschool robotics program is indeed a positive asset for multiple educational stakeholders: students, teachers, and undergraduate engineering majors.

\section{A. Growth in Participation}

One criterion to measure the attractiveness of a program is by evaluating the number of participants in the program over time. Our local GEAR tournament has seen continuous growth over the last seven years, both in terms of number of schools participating as well as in number of individual participants. It was implemented in 2006 as part of a Texas Technology Workforce Development Grant ${ }^{11}$ which aimed at improving retention of electrical engineering students by offering them paid mentor positions at an early point in their degree program (freshman and sophomore year). The challenge was first piloted at a single elementary school with 20 students on four consecutive Saturdays to evaluate its feasibility and to gain some experience. The first non-pilot GEAR tournament was offered to local elementary schools in 2007 with 12 participating schools all of which participated again in 2008. In 2009, participation was opened to middle schools based on requests from middle school teachers who had heard about it from their elementary school colleagues, parents of $6^{\text {th }}$ graders who participated in GEAR in elementary school, or through the local media. Since 2010, separate competitions for elementary schools and middle schools have been held in order to accommodate the increased number of participants. While we sent out flyers to local schools in 2007 and expended the number of schools participating significantly by advertising the event through electronic newsletters sent out by the Texas Education Service Centers in 2011, many first-time participating teachers heard about the competition from their colleagues at other schools.

11 Texas Higher Education Coordinating Board Technology Workforce Development Program, (2006), http://www.thecb.state.tx.us/index.cfm?objectid=9B6BC3F5-F808-5745-885FDE77874A96E6, accessed February 2013. 
Table 1 shows the number of schools and number of teams that participated in our GEAR competition each year separated by school type: elementary schools (K-5 $5^{\text {th }}$ grade) and middle school $\left(6^{\text {th }}-8^{\text {th }}\right.$ grade). As mentioned above, GEAR was not offered to middle schools until 2009 and in that year a joint competition was held for both school types. From 2009 on a constant growth in the number of participating schools can be observed from the table. It is graphically shown in Figure 1. The decrease in participation from 2008 to 2009 is due to the transition made in LEGO robotics kits at that time. Some schools which already owned the older LEGO RCX kits never started using the at-the-time newly introduced LEGO MINDSTORMS NXT kits and stopped participating. Since each school could participate with up to 10 teams, Table 1 also shows the growth in number of participating teams for each year. While there are no restrictions on team sizes, observations at the competitions have revealed that most teams consist of 2-4 members. Some school districts had teams with members from grades 4-7, thus the uncertainty in number of elementary and middle school teams for 2009. While we originally started by offering GEAR to elementary schools only, its recent growth both in number of schools as well as number of teams is among middle schools. Information from teachers provided on the registration forms reveals that many middle schools have ways to integrate GEAR into robotics or technology classes and that those teachers had experience with LEGO robotics prior to participating in GEAR. As motivation to participate in GEAR these teachers often mentioned the application of robotics tasks that the competition theme provides and the added competitive component.

Table 1: Number of schools and teams participating in the TTU GEAR competition by year

\begin{tabular}{|c|c|c|c|c|c|}
\hline \multirow[t]{2}{*}{ Year } & \multicolumn{2}{|c|}{ Elementary Schools (K-5) } & \multicolumn{2}{|c|}{ Middle Schools (6-8) } & \multirow[t]{2}{*}{ Total \# of teams } \\
\hline & \# of schools & \# of teams & \# of schools & \# of teams & \\
\hline 2007 & 12 & not available & not offered & N/A & not available \\
\hline 2008 & 13 & not available & not offered & N/A & not available \\
\hline 2009 & 7 & $\begin{array}{c}\text { 30-39 (Some mixed } \\
\text { teams) }\end{array}$ & 6 & $\begin{array}{c}11-20 \text { (Some mixed } \\
\text { teams) }\end{array}$ & 50 \\
\hline 2010 & 9 & 50 & 13 & 47 & 97 \\
\hline 2011 & 16 & 75 & 19 & 76 & 151 \\
\hline 2012 & 20 & 88 & 29 & 129 & 217 \\
\hline
\end{tabular}

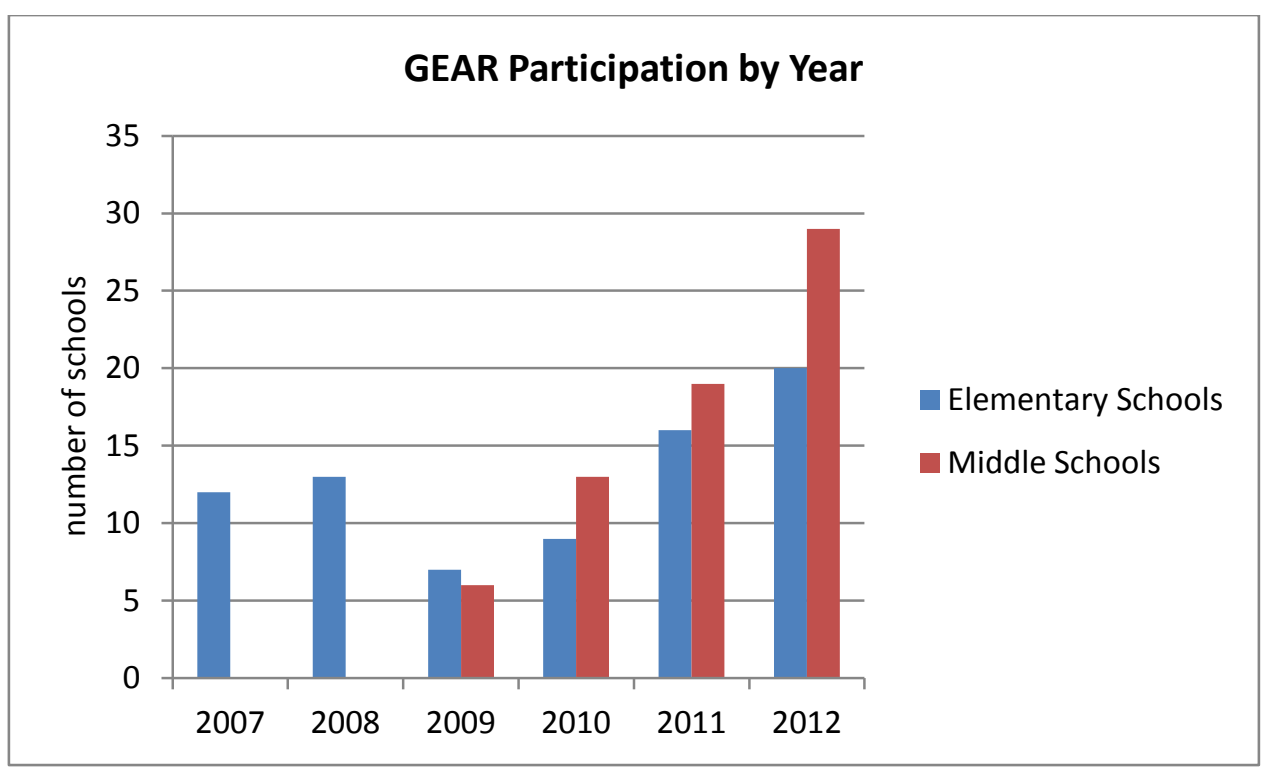

Figure 1: Number of schools participating in our GEAR competition

Since its inception, 28 different elementary schools and 35 different middle schools have participated in the annual TTU GEAR competition. Of these schools, $66 \%$ of the elementary schools and 54\% of the middle schools are classified as Title 1 schools, see Table 2, which further splits Title One schools into three different categories based on the percentage of low income students at these schools $(<70 \%, 70 \%-90 \%,>90 \%)$. Our competition can thus be considered as successful in attracting students from underserved populations. The majority of Title 1 schools checked out LEGO MINDSTORMS NXT kits from us and feedback from teachers confirmed that they 
would not have been able to participate if there was a registration fee associated with the competition or if they had to invest in their own LEGO kits. This indicates that, to gain or maintain a presence in Title 1 schools, monetary barriers to entry such as registration fees or payment for kits should be low or non-existent.

Table 2: Percentage of Title 1 schools that participated in GEAR robotics and percentage of low income student population in Title 1 schools (data provided by the Texas Higher Education Agency ${ }^{12}$ )

\begin{tabular}{|c|c|c|}
\hline & Elementary Schools (K-5) & $\begin{array}{c}\text { Middle Schools (6-8) } \\
\end{array}$ \\
\hline Non-Title 1 schools & $34 \%$ & $46 \%$ \\
\hline Title 1 schools (total \%) & $66 \%$ & $54 \%$ \\
\hline$<70 \%$ low income student population & $33 \%$ & $37 \%$ \\
\hline $70 \%-90 \%$ low income student population & $22 \%$ & $17 \%$ \\
\hline$>90 \%$ low income student population & $11 \%$ & $0 \%$ \\
\hline
\end{tabular}

Apart from being able to attract schools to GEAR, annual repeated participation is another indicator of offering a program that teachers and participants consider valuable. Most schools participate in the GEAR competition on an annual basis. Over the years, eight elementary schools stopped participating GEAR. In five cases the school administration had decided that they would not continue in the competition any longer (reasons are unknown), in two cases the robotics teacher retired and nobody took over that responsibility, and the reason for the last case is unknown. Out of the six middle schools that stopped participating, two cases were due to lack of interest among students (too many other conflicting activities students were engaged in), two due to teacher retirement, in one case a combined elementary/middle school moved participation from middle school to elementary school, and the last case was a one-time participation of a group of students who had done GEAR in elementary school and participated again their first year in middle school, In summary, a large number of schools annually participate in GEAR (71\% of all elementary schools and $83 \%$ of all middle schools).

Figure 2 shows for how many consecutive years the schools that participated in the 2012 competition have been participating in GEAR (divided into elementary schools in the top graph and middle schools in the bottom). It also provides information about how far the schools are away from the tournament location, split into three categories: less than 15 miles, 15 to 50 miles, and over 50 miles. The one elementary school listed as "other" in Figure 2 participated in 2010 and 2012 but not in 2011 due to health issues of the robotics coach.

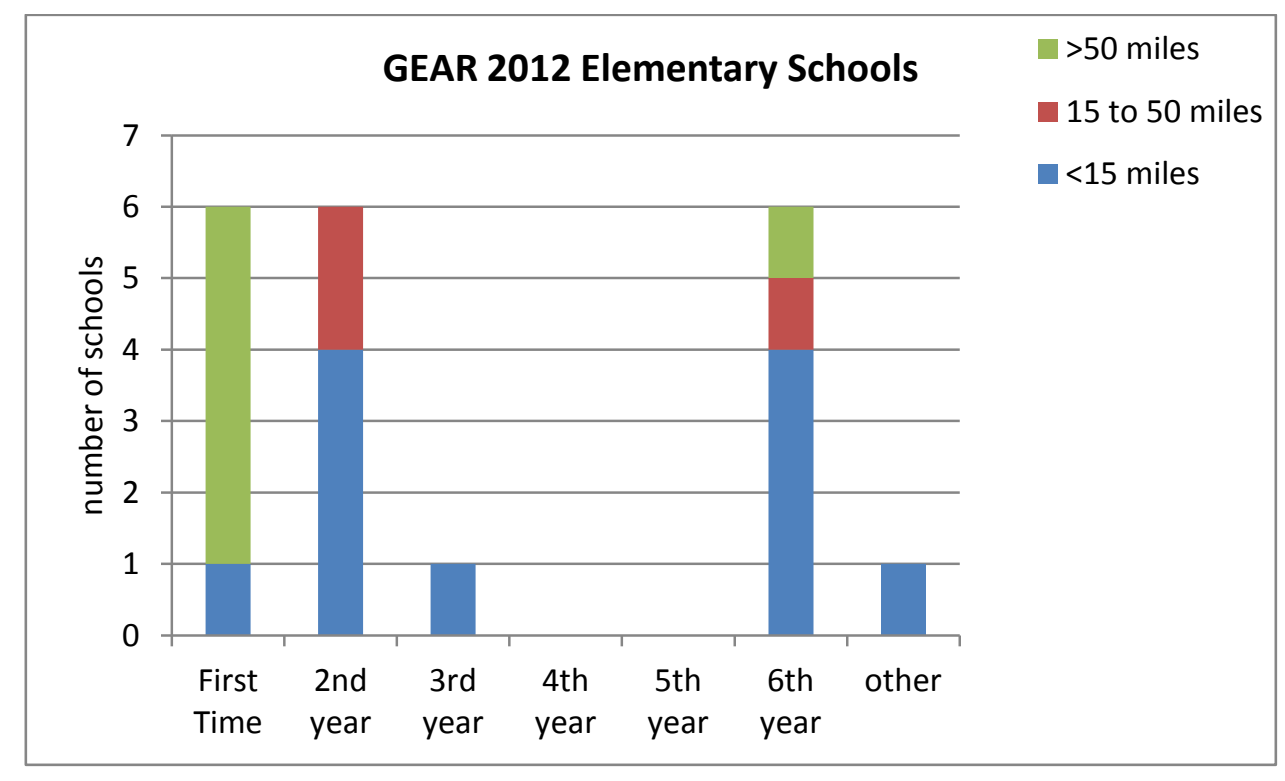

12 Texas Education Agency (TEA), Title 1 Campuses 2009-2010, http://www.tea.state.tx.us/index2.aspx?id=\%202147499694\&menu_id=798\&menu_id2=2147483722, accessed February 2013. 


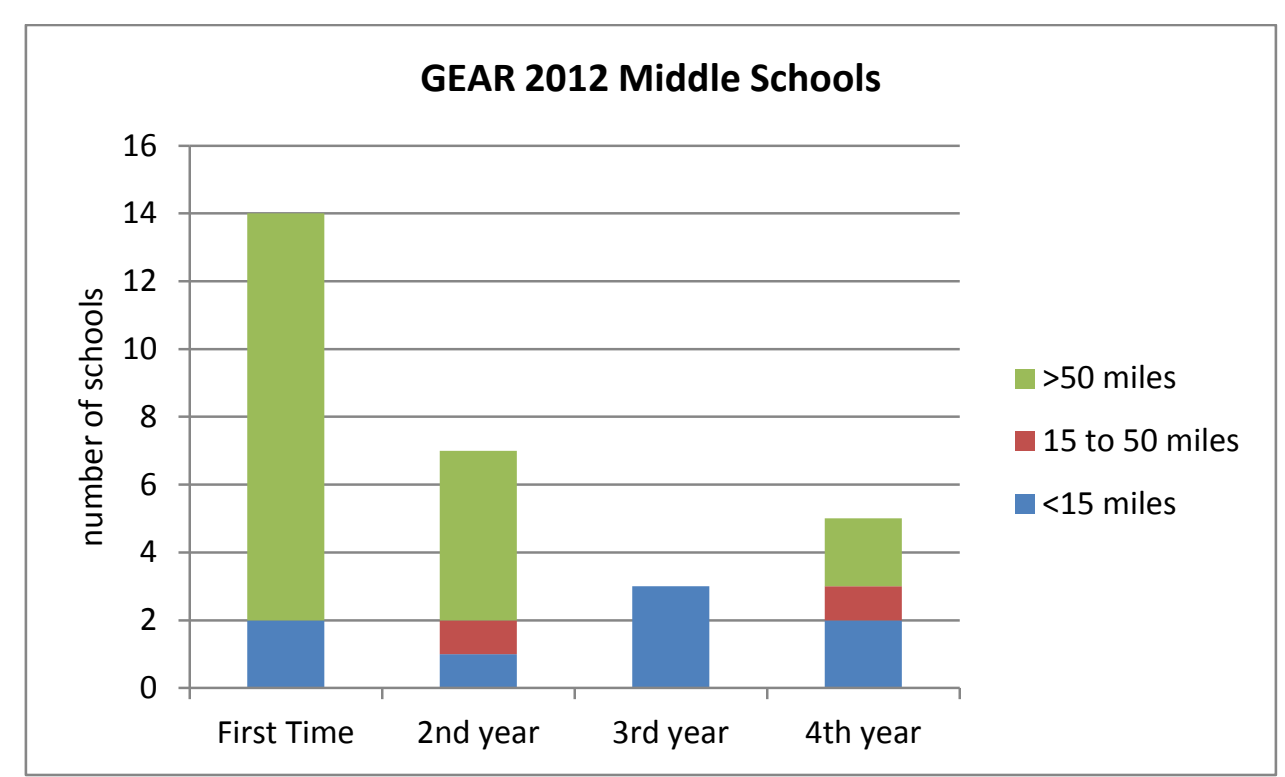

Figure 2: Number of consecutive years 2012 GEAR schools participated in the program, separated by school's distance from tournament location; top: elementary schools, bottom: middle schools

As can be seen from Figure 2, many of the schools that participate have been in the program for the whole of the program's existence: 6 schools of the possible 20 elementary schools have participated for six consecutive years and 5 schools of the possible 29 middle schools have participated for 4 consecutive years. The majority of schools are either first- or second-time participants or long-time veterans (as can be seen by the dip in the middle years of participation). We attribute this dip to schools deciding not to participate due to the new LEGO kits that came out about four years ago and to a lack of advertisement in those years. This is further evidence that these LEGO kits may need to be subsidized, particularly for Title 1 schools.

It is interesting to note that the majority of first-time participating schools (as of 2012) are from over 50 miles away (see Figure 3 for the geographical region participating schools are from). For middle schools, this also holds true for schools that participated since 2011. Most of these schools already had robotics programs in place and were looking for applications and/or challenges to incorporate into these LEGO robotics programs and to motivate their students. This may suggest that this program has become more widely known in the surrounding region, as well as indicate a future need for a locally-based program that may not require the students to travel as far. Since those K-8 students who are more than 15 miles away do not benefit from the coaching of the engineering undergraduate mentors (due to time and travel constraints for the undergraduates), in the future, we may look into video conferencing alternatives to connect engineering undergraduate mentors with participants. However, this option may be limited by the lack of appropriate webcams and internet access in low-income elementary and middle schools as well as other factors like the inability of the undergraduate mentors to interact with participants on a personal level or physically manipulate objects in front of them. Due to the fact that West Texas is relatively rural and geographically spread out, this may be a limiting factor inherent in this area alone and may not be faced by other programs in other geographic regions.

Comparing Figure 1 with Figure 2, one notices that six of the twelve initially participating elementary schools (50\%) have participated every year from 2007-2012. The same holds true for five of the six middle schools that participated in GEAR in 2009. In all these cases the participants were coached by the same teacher all those years, thus suggesting that the program's relationship with the school over time and professional relationships with specific teachers matter for continued participation.

While we can demonstrate growth in participation by number of schools and numbers of teams, as shown in Table 1 and Figure 2, the only longitudinal data that were collected on an individual participant basis was the preand post-test survey during 2010 (results are discussed below in section C). Given the flexibility of implementation 
at the school level (a criterion that we consider as one of the success factors of our program), many different constraints exist with respect to who gets to participate in the program. Some schools limit participation to a single grade level; others have developed a sophisticated application process including tryouts. A general consensus among GEAR coaches is that students participating in GEAR must have good academic standing, and interest in robotics, and be available for after school meetings. Thus, given the variance in selection processes and student populations between schools, it is likely that this program's effects are mediated by school setting and student demographics.

Figure 3 shows the geographic region in West Texas of schools that participated in GEAR in 2012. While 11 of the 20 elementary schools $(55 \%)$ were located within a 15 miles radius of the Texas Tech University campus, only 8 of the 29 middle schools $(24 \%)$ were located within this radius and $19(66 \%)$ traveled over 50 miles, two of them $(7 \%)$ close to 300 miles, in order to participate in the competition, thus signaling their commitment to the program and their assessment of the program's importance to their students.

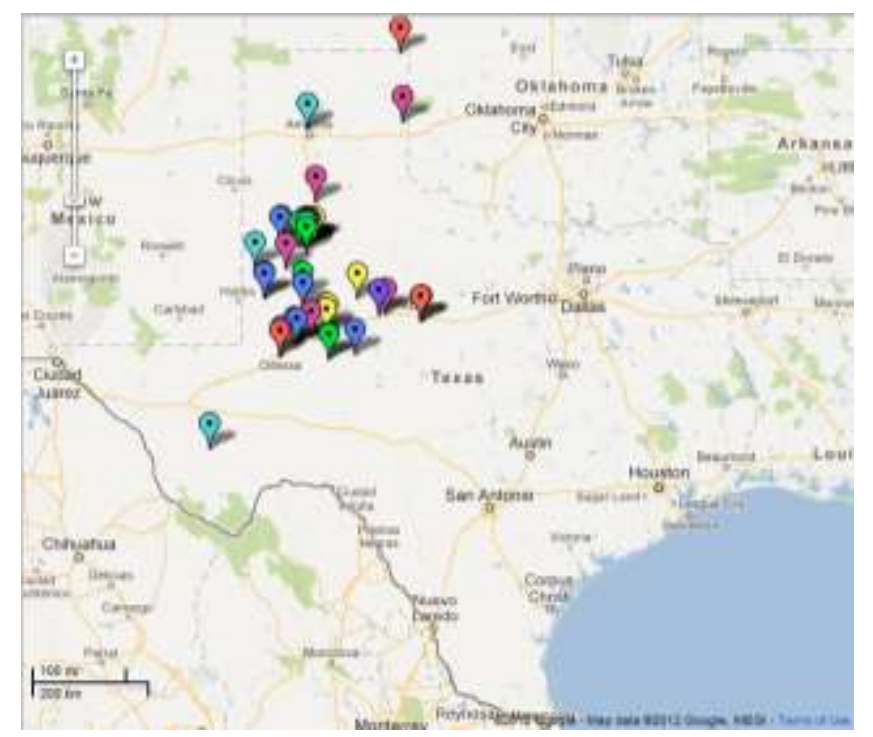

Figure 3: Location of schools that participated in our GEAR competition 2012

\section{B. Team Demographics}

Although no longitudinal data over the course of the entire six year program were collected, data from the pre- and post-test survey as well as the team demographic forms allow us to see a snapshot of student and school demographics from 2010-2012. Tables 3 and 4 summarize the information obtained from these sources.

Table 3: Gender and ethnicity of participants (PI: Pacific Islander)

\begin{tabular}{|c|c|c|c|c|c|c|c|c|}
\hline Year & Male & Female & African Amer. & Amer. Indian & Asian/PI & Hispanic & White & Other \\
\hline 2010 & $56 \%$ & $44 \%$ & $7.1 \%$ & $<1 \%$ & $1.8 \%$ & $36.4 \%$ & $47.6 \%$ & $6.2 \%$ \\
\hline 2011 & $67 \%$ & $33 \%$ & $4.7 \%$ & $<1 \%$ & $2.2 \%$ & $37.4 \%$ & $48 \%$ & $7.6 \%$ \\
\hline 2012 & $67 \%$ & $33 \%$ & $3.8 \%$ & $<1 \%$ & $2.1 \%$ & $32.1 \%$ & $55.2 \%$ & $6.6 \%$ \\
\hline
\end{tabular}

Table 4: Grade level distribution of participants

\begin{tabular}{|c|c|c|c|c|c|c|c|}
\hline Year & $\mathbf{2}^{\text {nd }}$ & $\mathbf{3}^{\text {rd }}$ & $\mathbf{4}^{\text {th }}$ & $\mathbf{5}^{\text {th }}$ & $\mathbf{6}^{\text {th }}$ & $\mathbf{7}^{\text {th }}$ & $\mathbf{8}^{\text {th }}$ \\
\hline 2010 & & $1.8 \%$ & $14.7 \%$ & $24 \%$ & $26.7 \%$ & $17.8 \%$ & $14.2 \%$ \\
\hline 2011 & $0.6 \%$ & $4.9 \%$ & $12.5 \%$ & $30.9 \%$ & $19.2 \%$ & $16.6 \%$ & $13.7 \%$ \\
\hline 2012 & $0.9 \%$ & $1.5 \%$ & $18.6 \%$ & $23.7 \%$ & $17.5 \%$ & $25.2 \%$ & $11.7 \%$ \\
\hline
\end{tabular}

In 2010, students self-identified into racial groups. In 2011 and 2012, teachers categorized students by race. We believe that the drop in Hispanic student participation in 2012 is due to the missing team information sheets from 12 schools, many of which reported a high Hispanic population participating in GEAR in previous 
years. Each year, we observe a large number of female participants often organized in "all girls" teams. Table 3 reflects that about $1 / 3$ of the participants are girls in all three years. In 2010, the percentage of girls was even higher (44\%). In that year, however, one middle school, which had implemented GEAR as part of a required class, contributed data for all their students involved in robotics and not just the participants of the competition, which raised the number of participating females. Due to a lack of data, we cannot determine which students participated in competitions and in the program during school hours as opposed to those who participated in the program during school hours but did not participate in the competitions.

Table 4 shows that the majority of participants are from grade levels 4 through 7 . Students in grade levels K-2 typically do not have the necessary fine motor skills for the LEGO MINDSTORMS NXT kits. Third graders are often not considered due to the limited number of slots for participating. We have also observed that $8^{\text {th }}$ graders often move on to more elaborate robotics competition such as BEST (Boosting Engineering, Science, and Technology $)^{13}$, if offered at their school.

\section{Pre- and Post-Test Survey}

As mentioned in the methods section, we conducted a pre-test and post-test survey designed by Nugent, Barker, Grandgenett \& Adamchuk (2009) during the 2010 GEAR challenge to evaluate a LEGO robotics program for the same age group in Nebraska. The findings from this survey indicate that our robotics program is especially helpful for female participants, non-white Hispanics, and those who report that they receive a free school lunch, thus indicating low familial socioeconomic status. The survey consisted of 25 questions that could be grouped into three different concepts (Karp \& Schneider, 2011):

I. Attitudes toward the scientific method of investigation

II. Attitudes toward robotics and LEGO robotics in particular

III. Attitudes toward working in groups

A two-tailed paired sample t-test with significant level of 0.05 performed on all 225 participants and then on specific subgroups resulted in significant self-reported changes in attitude over the course of the program for some of the following questions:

- $\quad$ Question 2 (concept II): It is important for me to learn about robotics

- $\quad$ Question 7 (concept I): It is important for me to collect and interpret data to verify a prediction or hypothesis.

- $\quad$ Question 11 (concept I): I like using scientific methods to solve problems.

- Question 17 (concept I): I carefully analyzing a problem before beginning to develop a solution.

- Question 20 (concept II): I am certain I can fix the software program for a robot that does not behave as expected.

- Question 21 (concept II): I am confident that I can program a LEGO robot to follow a black line using a light sensor.

- Question 23 (concept III): I like to be part of a team that is trying to solve a problem.

Using data from all participants, a significant increase was seen for questions $7,11,20$, and 21, indicating an increased confidence in successfully solving robotics tasks at the end of the program and a higher appreciation for the scientific method of investigation. For specific coefficients and standard deviations (as well as precise significance levels), see Karp \& Schneider (2011).

Next, we looked at typically underrepresented groups. When performing the paired sample t-test for boys and girls separately, we saw a significant change toward a higher score for questions 11, 20, and 21 for girls while no significant change was seen among boys for any of these questions. This indicates an increase in affinity for scientific methods and increase in robotic confidence in females, a group typically underrepresented in this field.

\footnotetext{
${ }^{13}$ Boosting Engineering Science and Technology (BEST), http://www.bestinc.org/, accessed February 2013.
} 
When comparing Hispanic students against white students (not enough data was available for any of the other ethnic groups) a significant increase was observed among Hispanic participants for questions 17, 20, and 21 but not for white participants. Again, this indicates an increase in confidence and in problem analysis as part of scientific investigation. The only significant change in attitude that was found among white participants was a decrease in reporting enjoying solving a problem as a team - an unanticipated result. When looking at the same question result for girls, they actually scored higher in the post-test than in the pre-test but the change was not significant ( $\mathrm{p}<.05)$.

We also compared students who qualified for a free lunch program at school (low socio-economic standing) with those who do not. A significantly higher score was seen among the low socioeconomic status group for questions 7, 11, 17, and 21 in the post-test than in the pre-test. For the non-free lunch students, the only significantly higher score on the post-test than pre-test was on question 20 . This suggests that this program may cause an increase in understanding the importance of the scientific method as well as an increase in confidence for students from low-socioeconomic backgrounds. We were puzzled by the lack of significant increases in students from high socioeconomic backgrounds in confidence and importance of the scientific method, so asked teachers what they thought this might be due to. Many teachers suggested that the high socioeconomic students already had LEGO sets and other similar toys at home, so would enter the program already feeling confident in their ability to manipulate such toys. Last, in an effort to evaluate the longer term attitudinal changes among participants, we compared first time participants with participants with prior robotics experience. Among all subgroups, only participants with prior robotics experience showed a significantly increased perception of robotics being important to them, suggesting that the opportunity for repetitive exposure to robotics is important to achieve a long-lasting interest in STEM.

In summary, only a few questions resulted in a significant change in self-reported attitude between the pretest and post-test survey. However, most positive changes were observed among participants who are typically underrepresented in STEM fields.

\section{BENEFITS OF GEAR PARTICIPATION ACCORDING TO TEACHERS}

Our intention in offering GEAR is to expose young students at an early age to engineering through handson challenging activities that promote critical thinking, the engineering design process, application of sciences, and teamwork at an early age. Through the annually changing GEAR challenge and invited speakers at the on-campus kickoff event, we promoted engineering careers and a college-going mindset. This is particularly important for participants who do not have engineers or even college graduates in their family. According to teachers and participants, the GEAR events are often their first exposure to a university campus in an academic setting.

In our 2011 and 2012 team demographics form, we asked teachers open-ended questions to determine what they consider as benefits in participating in GEAR. Additionally, we spoke directly with teachers regarding what they considered the benefits and impacts of this program were on participating students. For both years and elementary and middle schools combined, we received open answers from 46 (21 elementary and 25 middle) teachers over the course of two years. According to the principles of grounded theory (Glaser \& Strauss 1967; Charmaz 2006), the answers were analyzed for common themes, then the frequency of each theme was determined. These concepts were not necessarily mutually exclusive - for example, a teacher might speak about the importance of learning how to persevere in problem-solving. This would be counted as both "problem-solving" and "perseverance." The results of the written answers are shown in Table 5. The teachers who participated in this program were universally enthusiastic about its impact on students and critical thinking skills:

The main benefits of participating in GEAR are as follows: practice and implementation of problem solving, communication, and team building skills. It also gives the students an opportunity to see places and have experiences they would normally not be able to, i.e. visiting [Texas Tech University] and working with robots.

By far, the most commonly teacher-reported benefit of participating in GEAR was an improvement in student teamwork skills, followed by problem solving and critical thinking, and then computer programming skills. Interestingly, other than computer programming, the application of math, sciences, engineering, and technology concepts was rarely mentioned by teachers as a benefit of GEAR participation, although many teachers noted that 
GEAR "recruited" students into these areas. Soft skills, such as persistency, time management, the challenging aspect of a competition, creativity, and the creation of a college going mindset were more commonly perceived as benefits, especially for Title 1 students. As one teacher put it:

Teamwork exposes students to higher order thinking skills, technology, science, and math. [It also is] exposing Title 1 students to a world of experiences that they would not have at any other place. It also is recruiting students from the 4th [grade] in the science and math areas.

Table 5: Benefits of participation in GEAR according to teachers

\begin{tabular}{|c|c|}
\hline 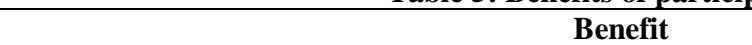 & Occurrence \\
\hline teamwork / cooperative learning & 40 \\
\hline problem solving & 34 \\
\hline critical thinking / higher order thinking & 13 \\
\hline introduction to computer programming & 13 \\
\hline challenge/competition & 9 \\
\hline new experiences / hands on activity / skill building & 9 \\
\hline Creativity & 8 \\
\hline travel / campus experience & 8 \\
\hline persistency, perseverance, patience, tenacity, dependability & 7 \\
\hline design / construction & 6 \\
\hline introduction to technology/technology skills & 5 \\
\hline gets them excited about STEM & 4 \\
\hline exposure to engineering & 4 \\
\hline self-esteem / confidence / success & 4 \\
\hline prepare for future & 4 \\
\hline application of science concepts & 3 \\
\hline using math skills & 2 \\
\hline outside the box thinking & 2 \\
\hline competition at no cost & 2 \\
\hline engineering process & 2 \\
\hline Excitement & 2 \\
\hline Motivation & 2 \\
\hline improvement in attitude and discipline & 2 \\
\hline planning / meeting deadline & 2 \\
\hline learn to reflect / observation of others & 2 \\
\hline communication skills & 2 \\
\hline Fun & 1 \\
\hline trial and error & 1 \\
\hline working with robots & 1 \\
\hline
\end{tabular}

Research performed by Duncan-Wiles, Jones, Diefes-Dux, \& Brophy (2012) regarding the implementation of engineering in the elementary and middle school curriculum has revealed a reluctance of elementary and middle school teachers to talk about engineering in class even after participation in teacher professional development. The authors state that while the teachers are implementing the engineering related activities covered in a professional development workshop, they rarely relate these activities to the field of engineering or the engineering design process (Duncan-Wiles et al. 2012). The fact that the teachers in our study predominantly spoke about critical thinking skills and team work and only mentioned "exposure to engineering" four times may be reflective of this reluctance. To calm those fears and provide an extra adult in the classroom with some expertise in engineering, the engineering undergraduate mentors bridge this gap.

\section{THE ROLE OF ENGINEERING MENTORS}

Providing engineering undergraduate students as mentors to local GEAR teams has turned out to be another success factor in attracting schools to participate in GEAR as well as in the program itself. Various successful formats of selecting engineering mentors have been tested during the last years. We originally started by offering paid mentor positions to electrical and computer engineering students as part of our Texas Workforce Development 
grant. ${ }^{14}$ Since 2010, a Service Learning section of ENGR 1315 Introduction to Engineering is offered every spring semester and mentoring local school teams is part of the service learning assignment (Karp, 2011). ENGR 1315 is a freshman level engineering course required by most engineering majors and pre-engineering students and is typically taken during their first year on TTU campus. Students in this service-learning section must choose to be a part of it and receive additional training in the university classroom concerning how to interact with K-8 students as well as how to work with the LEGO kits.

For first-time participating teachers, the availability of a mentor takes away a large part of the intimidation caused by the perceived requirement of being a robotics expert and technologically savvy. Engineering undergraduate mentors and teachers quickly form a symbiotic relationship: while the teacher organizes the classroom setting, selects participants, deals with behavioral and discipline issues, communicates with parents, and deals with other housekeeping tasks, the engineering undergraduate mentor becomes the technology and engineering expert who is responsible for software installation, and answering any type of questions regarding programming or robot design. Teachers from local schools annually request mentors for their teams. While some teachers only want one engineering undergraduate mentor for all their teams, others assign an engineering mentor to each of their teams. Teacher feedback on the team demographics forms does reveal that the performance of the mentors and quality of the mentoring varies by undergraduate student, but the majority of teachers were quite positive and grateful for their mentors. Some noted that having mentors of similar race to the student population was helpful in providing role models to students. Others were thankful for the extra hands and expertise in the classroom: "mentors were great and most needed because I have a large group."

Teachers annually request mentors to come to their school even if last year's mentors were only moderately helpful. No teacher has ever requested that no engineering mentor should come to their school. Even teachers who are robotics veterans and have participated in the program for several years appreciate the presence of the engineering mentors in the classroom. Having more adults in the classroom allows them to enroll more students in the program. "Mentors go a long way," said one veteran robotics teacher. He continued:

Students are more invested when their team has a mentor. Mentors are not too much different from the students and show them that they also can go to college one day. When having a mentor for each team, the competition is not only among the teams but also between the mentors, taking the competition to a whole different level and resulting in a larger variety of robot designs. Teams that have mentors practice explaining what they're doing to adults and perform better in the competition, when being interviewed by or negotiating with judges.

Another teacher who was particularly pleased with the 2012 mentoring experience wrote:

These guys were great! It was a bonus that they were also minorities. I always think it's great when our children get to see people "like them" being successful. They helped get the kids to think and did not just give them the solutions. This was an extremely positive experience for all involved this year. They were positive with the kids and talked to them appropriately. They were on time and if they couldn't make it they always let me know ahead of time.

Student mentors were equally positive about the experience, reporting that they enjoyed spending time with children and applying the skills that they were learning on the university level. Some reported that teaching the basic skills actually solidified higher-level concepts in their own minds, thus contributing to their own learning. Since students were receiving course credit for participating, it seems possible that they were also so positive about the experience when asked because their professor(s) were the ones questioning them. However, many have approached us after the course was completed to repeat that they "really enjoyed working with the school teams and learned something." Some students - particularly females - stay involved in the program in following years either as mentors or as hourly paid undergraduate assistants. Overall, we argue that mentoring elementary and middle school students during the eight week GEAR LEGO robotics competition teaches undergraduate students communication skills, critical thinking, problem solving, team work, professionalism, and leadership, i.e. skills that are hard to teach in a university classroom setting.

14 Texas Higher Education Coordinating Board Technology Workforce Development Program, (2006), http://www.thecb.state.tx.us/index.cfm?objectid=9B6BC3F5-F808-5745-885FDE77874A96E6, accessed February 2013.

50 Copyright by author(s) Creative Commons License CC-BY

2013 The Clute Institute 


\section{POSSIBLE LIMITATIONS}

While we overall found that the effects of this program are positive for all involved (the K-8 students, teachers, and undergraduate mentors), there are some limitations in this study that could be addressed in future research. First, students and teachers self-select into this program, possibly because of prior interest in robotics and/or engineering. Thus, excitement and knowledge about engineering and scientific skills may not be only due to participation in this program. And, while we considered the flexibility and adaptability of this program to be a strength in recruiting schools and participants, the fact that it was used differently in different schools (during school hours as opposed to an after-school program) and different schools had different criteria for students to participate (everyone who applies versus a "tryout" system) may limit the comparability of data between schools. Regarding effects on teacher and student knowledge, we are unsure whether teacher comfort with engineering and scientific concepts and student knowledge have been improved, since the majority of teachers focused on the improvement in student critical thinking and teamwork skills rather than STEM concepts when asked about the benefits of this program. Additionally, teacher and participant response rates to questionnaires/team forms varied between 56 to 88 $\%$, indicating that our data may not be a complete picture of all who participated in this program.

\section{$8 \quad$ CONCLUSIONS}

We have described the six year long successful implementation of a robotics program for elementary and middle school students that not only benefits the teacher and K-8 student participants, but also college level engineering students who serve as mentors to local teams. Some of the causes of this success are the flexibility of the implementation at the organizer and the school level, the fact that participation is at no cost, and the synergistic relationship between teachers and engineering students. In terms of the impact of this program, it has seen significant growth over the six years of its existence and continues to attract a diverse body of participants and a large percentage of Title 1 schools.

Regarding individual-level effects on K-8 students, this program has been shown to have a positive effect on the confidence levels and attitudes towards the scientific method and robotics in female students as well as Hispanic students. Since these are traditionally underserved populations in the STEM fields, reaching students while they are still in early years of their schooling may aid in increasing their populations at the university and professional level. Overall, students report enjoying this program and learning about robotics. Students who receive free lunch (thus signaling low familial socioeconomic status) also report increased confidence levels as well as knowledge and use of the scientific method. Teachers report that their students have improved on critical thinking and teamwork skills, and also state that they enjoy having the program (and its undergraduate mentors) in their classrooms for role-modeling purposes for the K-8 participants. Additionally, this program has had a positive effect on those undergraduates who are already training to be professional engineers in terms of ability to communicate to different audiences, knowledge formation, and professional skills such as punctuality and preparation. They also report that their knowledge of the some fundamental concepts is improved by having to teach them in detail to younger students.

Overall, sustainability of this program beyond the initial grant funding period was achieved by exploiting its educational opportunity and involving engineering freshmen in form of a service learning project. In addition, funding from various companies and foundations was obtained, thus suggesting that it is a method for successfully melding university service-learning, corporate sponsorship, and knowledge acquisition at the elementary and middle school levels.

\section{AUTHOR INFORMATION}

Tanja Karp, Dept. of Electrical and Computer Engineering, Whitacre College of Engineering, Texas Tech University, Box 43102, Lubbock, TX 79409-3102. E-mail: tanja.karp@ttu.edu (Corresponding author)

Tanja Karp received the Dipl.-Ing. degree in electrical engineering (M.S.E.E.) and the Dr.-Ing. degree (Ph.D.) from Hamburg University of Technology, Hamburg, Germany. She is currently an associate professor of electrical and computer engineering at Texas Tech University. Since 2006 she has been the organizer of the annual Get Excited 
About Robotics (GEAR) competition for elementary and middle school students in Lubbock. Her research interests include engineering education and digital signal processing,

Patricia Maloney, Dept. of Sociology, Anthropology, and Social Work, College of Arts and Sciences, Texas Tech University, Box 43102, Lubbock, TX 79409-1012. E-mail: patricia.maloney@ttu.edu

Patricia Maloney holds a BA in sociology/Classical Studies and M.Ed. from the University of Pennsylvania as well as a M.A. in sociology, M.Phil., and a Ph.D. in sociology from Yale University. She is currently an assistant professor of sociology at Texas Tech University, where her research predominantly focuses on the educational system in America.

\section{REFERENCES}

1. Bardack, S., Seidel, D., Seiter, L., and Lampron, S. (2011), Program for the Education of Children and Youth Who Are Neglected, Delinquent, or at Risk of Educational Failure (Title I, Part D). US Dept. of Education, Annual Program Performance Report, School Year 2008-2009, 65 pages, https://www.ncjrs.gov/App/Publications/abstract.aspx?ID=260282.

2. Caron, D., (2010). Competitive Robotics Brings Out the Best in Students. TechDirection, $21-23$.

3. Chambers, J., and Carbonaro, M. (2003). Designing, Developing, and Implementing a Course on LEGO Robotics for Technology Teacher Education. Journal of Technology and Teacher Education, 11(2), 209241.

4. Charmaz, K. (2006). Constructing grounded theory: A practical guide through qualitative analysis. Thousand Oaks, CA: Sage.

5. Duncan-Wiles, D., Jones, T. R., Diefes-Dux, H., Brophy, S., (2012). Work in Progress: Changes in Elementary Teachers' Noticing of Engineering Pre/Post Professional Development with Engineering. Proc. ASEE/IEEE Frontiers in Education Conference, October.

6. Elementary and Secondary Education Act, (1965). Title I — Improving The Academic Achievement Of The Disadvantaged, [Online], http://www2.ed.gov/policy/elsec/leg/esea02/pg1.html

7. Franz, D., and Elmore, B. B., (2009). Work in Progress - Collaborative Outreach to "At risk" Middle School Students using LEGO Robotics. Proc. 39th ASEE/IEEE Frontiers in Education Conference, pp. 807-808.

8. Glaser, B. G., \& Strauss, A. L. (1967). The discovery of grounded theory: Strategies for qualitative research. Aldine de Gruyter.

9. Grimes J., Seng J., (2008). Robotics Competition: Providing Structure, Flexibility, and an Extensive Learning Experience. Proc. 38th ASEE/IEEE Frontiers in Education Conference, Saratoga Springs, NY, DOI:10.1109/FIE.2008.4720494.

10. Habash, R. W. Y., Suurtamm, C. (2010). Engaging High School and Engineering Students: A Multifaceted Outreach Program Based on a Mechatronics Platform. IEEE Transactions on Education, 53( 1), 136-143.

11. Hobson, R. S, (2000). The changing face of classroom instructional methods: Service learning and design in a robotics course. Proc. 30th ASEE/IEEE Frontiers in Education Conference, October 18 - 21, Kansas City, MO.

12. Karp, T. and Schneider, A., (2011). Evaluation of a K-8 LEGO Robotics Program. Proc. IEEE/ASEE Frontiers in Education Conference, pp. T1D 1-6, Rapid City, SD, USA, October.

13. Karp, T., (2011). Teaching a Service Learning Introductory Engineering Course - Lessons Learned and Improvements Made. Proc. IEEE/ASEE Frontiers in Education Conference, pp. F1E 1-5, Rapid City, SD, USA, October.

14. Karp, T., Gale, R., Lowe, L., Medina, V., Beutlich, E., (2010). Generation NXT: Building Young Engineers with LEGO's. IEEE Transactions on Education, Special Issue on Outreach to Prospective Electrical, Electronic, and Computer Engineering Students, 53(1), 80-87.

15. Liu, E.Z. F.; Lin, C.-H; Chang, C. S., (2012) Student Satisfaction and Self-Efficacy in a Cooperative Robotics Course. Social Behavior and Personality: An International Journal, 38(8), 1135-1146.

16. Mauch, E., (2002). Using Technological Innovation to Improve the Problem-Solving Skills of Middle School Students - Educators' Experiences with the LEGO Mindstorms Robotic Invention System. The Clearing House, 74(4), 211-213. 
17. Mitchell, R., Warwick, K., Browne, W. N., Gasson, M. N., Wyatt J. (2010). Engaging Robots: Innovative Outreach for Attracting Cybernetics Students. IEEE Transactions on Education, 53(1), 105-113.

18. Nugent, G., Barker, B., Grandgenett, N., and Adamchuk, V., (2009). The Use of Digital Manipulatives in K-12: Robotics, GPS/GIS and Programming. IEEE/ASEE Frontiers in Education Conference, San Antonio, TX, pp. M2H1-6.

19. Nugent, G., Barker, B. S., \& Grandgenett, N. (2012). The Impact of Educational Robotics on Student STEM Learning, Attitudes, and Workplace Skills. In B. Barker, G. Nugent, N. Grandgenett, \& V.

Adamchuk (Eds.), Robots in K-12 Education: A New Technology for Learning (pp. 186-203). Hershey, PA.

20. Osborne, R. B., Thomas, A. J., and Forbes, J., (2010). Teaching with Robots: a Service-Learning Approach to Mentor Training. SIGCSE Bulletin, 41(1), 172-176.

21. Robinson, M. (2005). Robotics-driven activities: Can they improve middle school science learning? Bulletin of Science, Technology \& Society, 25(1), 73-84.

22. Texas Education Agency (TEA), (2012), Title 1 Campuses 2009-2010. [Online], http://www.tea.state.tx.us/index2.aspx?id=\%202147499694\&menu_id=798\&menu_id2=2147483722

23. Williams, D. C., Ma, Y., Prejean, L., Ford, M. J., and Lai, G. (2007). Acquisition of Physics Content Knowledge and Scientific Inquiry Skills in a Robotics Summer Camp. Journal of Research on Technology in Education, 40(2), 201-216. 
NOTES 